\section{Primary Health Care: An Overview}

Mohammad Wael Daboul*

Laboratory Medicine Specialty Degree, Ministry of Health, Syria

Globalization is putting the social cohesion of many countries under stress [1]. People are increasingly impatient with the inability of health services to deliver levels of national coverage that meet stated demands and changing needs. Health systems, as key constituents of the architecture of contemporary societies, are clearly not performing as well as they should. Due to failure to provide services in ways that correspond to expectations, health systems need to respond better and faster to the challenges of a changing world. Primary Health Care (PHC) is the address. The Declaration of Alma-Ata was clear about the values pursued: social justice and the right to better health for all, participation and solidarity [2].

The PHC values to achieve health for all require health systems that put people at the center of health care [3]. Taking into account citizens' expectations about health and health care and ensuring that their voice and choice decisively influence the way in which health services are designed and operate is a major requirement [4].

The ultimate goal of primary health care is better health for all. WHO has identified five key elements to achieving that goal [5]:

- Reducing exclusion and social disparities in health (universal coverage reforms)

- Organizing health services around people's needs and expectations (service delivery reforms)

- Integrating health into all sectors (public policy reforms)

- Pursuing collaborative models of policy dialogue (leadership reforms)

- Increasing stakeholder participation

As a strategy, primary health care focuses on maximizing the involvement of the community; including all relevant sectors but avoiding duplication of services; and using only health technologies that are accessible, acceptable, affordable and appropriate [6]. Primary health care relies on individual and community strengths (assets) and focuses on opportunities for change (needs). PHC needs to be delivered close to the people; thus, should rely on maximum use of both lay and professional health care practitioners and includes the following eight essential components:

1. Education for the identification and prevention/control of prevailing health challenges.

2. Proper food supplies and nutrition; adequate supply of safe water and basic sanitation.

3. Maternal and child care, including family planning.

4. Immunization against the major infectious diseases.

5. Prevention and control of locally endemic diseases.

6. Appropriate treatment of common diseases using appropriate technology.

7. Promotion of mental, emotional and spiritual health.

8. Provision of essential drugs [2].
Through integration of the concepts of empowerment, communityaction and transformative learning, we will be able to learn how best to transform our present sick-cure medical system of primary care into a model of primary health care which reflects values and works with the community on opportunities for change [7]. Progress is possible. It can also be accelerated [8]. The accelerated technological revolution is multiplying the potential for improving health [9]. Shifting of emphasis away from dependence on health care practitioners and towards personal involvement; as well as, the need for more than improved health and medical services was echoed in the Ottawa Charter for Health Promotion (WHO, 1986).

A coordinated approach to this complex, multi-faceted, intersectoral priority for transforming the health care system can only by explored through an interdisciplinary approach that engages all of the stakeholders in the process (individuals, communities, health care practitioners, decision-makers and policy makers).

\section{References}

1. WHO (2013) The world health report: Introduction and Overview.

2. Primary health care: report of the International Conference on Primary Health Care (1978). Alma-Ata, USSR, 6-12.

3. WHO (2007) People at the center of health care: harmonizing mind and body, people and systems. Geneva.

4. The Ljubljana Charter on Reforming Health Care, 1996. Copenhagen, World Health Organization Regional Office for Europe, 1996.

5. WHO (2013) Primary health care.

6. Definition of Primary Health Care (2011) University of Saskatchewan, College of Medicine.

7. Ramsden VR, Integrated Primary Health Care Research Team (2003) Learning with the community. Evolution to transformative action research. Can Fam Physician, 200-202.

8. World Health Statistics 2008. Geneva, World Health Organization, 2008

9. WHO (2013) Responding to the challenges of a changing world. The world health report.
*Corresponding author: Dr. Mohammad Wael Daboul, Laboratory Medicine Specialty Degree, Ministry of Health, Damascus, Syria, Tel: 334-9950; Fax: 3349951; E-mail: idaboul@scs-net.org

Received April 16, 2013; Accepted April 24, 2013; Published April 28, 2013

Citation: Daboul MW (2013) Primary Health Care: An Overview. J Gen Pract 1: 102. doi: $10.4172 / 2329-9126.1000102$

Copyright: (c) 2013 Daboul MW. This is an open-access article distributed under the terms of the Creative Commons Attribution License, which permits unrestricted use, distribution, and reproduction in any medium, provided the original author and source are credited. 